\title{
Online Dispute Resolution: an Artificial Intelligence Perspective
}

\author{
Davide Carneiro ${ }^{a}$, Paulo Novais ${ }^{a}$, Francisco Andrade ${ }^{b}$, John Zeleznikow ${ }^{c}$, José Neves ${ }^{a}$ \\ ${ }^{a}$ University of Minho, Department of Informatics, Braga, Portugal \\ \{dcarneiro, pjon, jneves\}@di.uminho.pt \\ b Universidade do Minho, Law School, Braga, Portugal \\ fandrade@direito.uminho.pt \\ ${ }^{c}$ Victoria University, School of Management and Information Systems, Melbourne, Australia \\ john.zeleznikow@vu.edu.au \\ Corresponding Author: \\ Paulo Novais \\ Universidade do Minho \\ Department of Informatics \\ Campus of Gualtar \\ 4710 -057, Braga, Portugal \\ Tel.: +351253604 437 \\ Tel.: +351253604470 \\ Fax.: +351253604 471 \\ E-mail: pjon@di.uminho.pt
}

\begin{abstract}
Litigation in court is still the main dispute resolution mode. However, given the amount and characteristics of the new disputes, mostly arising out of electronic contracting, courts are becoming slower and outdated. Online Dispute Resolution (ODR) recently emerged as a set of tools and techniques, supported by technology, aimed at facilitating conflict resolution. In this paper we present a critical evaluation on the use of Artificial Intelligence (AI) based techniques in ODR. In order to fulfill this goal, we analyze a set of commercial providers (in this case twenty four) and some research projects (in this circumstance six). Supported by the results so far achieved, a new approach to deal with the problem of ODR is proposed, in which we take on some of the problems identified in the current state of the art in linking ODR and AI.
\end{abstract}

Keywords Alternative Dispute Resolution, Online Dispute Resolution, Artificial Intelligence

\section{Introduction}

Conflicts are universal and thus there is an immense need to develop processes to minimise, manage and hopefully decide on them. The ideal dispute resolution process is one in which the two parties are better at the end of the course of action than they were at the beginning. Unfortunately, not all disputes take or may take this path. We believe hi-tech solutions may improve the overall outcome of the dispute resolution practices.

Although the term dispute resolution is from time to time used to describe Alternative Dispute Resolution (Brown \& Marriott, 1999) methods, in a broad mode it marks out a process in which two or more parties engage in order to situate their differences. In that sense, dispute resolution can be divided into two main tendencies: Judicial Dispute Resolution and Alternative Dispute Resolution.

The most common form of Judicial Dispute Resolution is litigation, opposing a plaintiff and a defendant. The legal system has the coercive power to enforce an outcome. This means that at the end of the process, the parties are bound to the decision of the court, although in some cases parties may appeal to other instances. 
Outcomes are decided either by a judge, a jury or a combination of both, taking into account the facts presented by the parties and the application of The Law. All these processes are very formal and are defined by rules established by a legislature. Litigation is generally seen as an inefficient process, in which the most important disadvantages are high costs and long lasting for the way out of cases. However, another important characteristic is that court rooms are generally highly competitive milieus, in which parties and their representatives will blindly pursue the maximization of their own personal profit, without any regards for the other party's interests. This constitutes the main obstacle for the achievement of a mutually satisfactory outcome, increasing the dissatisfaction of the parties and consequently the number of appeals, contributing to a slower and more inefficient judicial system.

In order to counter this trend, some extrajudicial dispute resolution methods started to be adopted by courts as a first attempt to solve a case before advancing to litigation. Some of these methods include a number of traditional ones such as arbitration, or others like collaborative law or mediation, among others. These can also be used independently by parties, with the assistance of institutions that do not make part of the judicial system. The steady development of this trend on dispute resolution is due to a perception of greater flexibility, lower costs than those of litigation and faster resolution of disputes. Parties will also often refer as advantages the increased privacy and fewer formalities.

In this paper we make a critical analysis of a number of commercial ODR providers and research projects. We do it from an Artificial Intelligence (AI) point of view, with the objective of determining how AI techniques can be used to improve the current state of the art in this field. Moreover, we present the approach we are following, in line with the conclusions achieved with an analysis of the state of the art.

\section{Dispute Resolution}

If we are looking for understanding the need for alternative methods of dispute resolution, we might as well look at a sentence by Abraham Lincoln which is still quite up to date: "Discourage litigation, persuade your neighbour to compromise where you can. Point out to them how the nominal winner is often the loser... in expenses and waste of time". Alternative Dispute Resolution refers to mechanisms that aim to solve disputes without recurring to the traditional judicial process, i.e. litigation in courts. Online Dispute Resolution refers to the use of these mechanisms in a technological context, either supported by technology or under a virtual computational environment. Historically, alternative methods have faced some resistance but they have eventually become used by both the legal system and the parties involved as the first stage to solve a dispute. There are even countries in which parties are encouraged or required to try some kind of alternative method before advancing into court.

\subsection{Alternative Dispute Resolution}

Some main alternative forms of conflict resolution can be identified. Negotiation (Raiffa, 2002) is a collaborative and informal process by means of which parties communicate and, without any external influence, try to achieve an outcome that can satisfy both. Negotiation is widely used in the most different fields such as legal proceedings, divorces, parental disputes or hostage situations, just to name a few. There are many ways of organizing the several negotiation techniques. From the perspective of (Walton \& McKersie, 1991), negotiation can be classified as a distributive or integrative approach.

In the former one, the items in dispute are seen as something that can be divided and distributed by the parties in an attempt to maximize their satisfaction. In the integrative one, the problem is expected to have more solutions than the ones visible at first sight. In these types of problems parties try to bring to the table as much interests as possible so that there are more valuable items with which to negotiate. This type of negotiation is also known as interest-based as the parties try to combine their interests and find points in which the interests of both are satisfied. By doing so, 
more mutually satisfactory outcomes are achieved. This makes integrative negotiation more desirable than distributive.

Another form of conflict resolution is mediation (Brown \& Marriott, 1999), in which the parties in dispute are guided by a 3 rd neutral and independent entity who tries to guide the process to an outcome that may satisfy both parties. In this approach, like in negotiation, both parties decide about the outcome instead of it being imposed by the nonaligned one, but with its added assistance. The nonaligned is chosen by the parties and has no authority for deciding on the outcome of the dispute but only for guiding and assisting them throughout it. This should be done by maintaining the parties focused on the subject of the dispute and by facilitating all the interaction and communication between them. The mediators are hence essential as their skills and aptitudes may represent the success or failure of the dispute resolution process.

We can also mention arbitration (Bennett, 2002), a method in which the two parties also use the help of a 3rd independent and neutral entity for solving a dispute but, contrary to mediation, this entity has no active role on helping the parties throughout all the process. In this approach the nonaligned party, the arbitrator, simply hears the parties and, based on the facts presented, takes a decision without influencing the parties during their presentations. Traditionally, the outcome of an arbitration process is binding, i.e., there is a final enforceable award that the parties will respect. However, arbitration can also be non-binding.

Finally, another alternative process is conciliation, which is run by a conciliator that meets the parties separately and aims at the resolution of their differences. The conciliator should be an expert with skills that allow him/her to lower tensions between the parties as a first stage for finding common ground. Then, he/she should communicate effectively with the parties in order to understand all the issues that generated the dispute. After doing this, the conciliator should be able to provide technical assistance to the parties as needed, so that they may have access to all the important information in order to take better decisions. Finally, the conciliator should explore all the potential paths for solutions and, at the end, achieve a negotiated settlement.

\subsection{Online Dispute Resolution}

On-line activities, such as the use of e-commerce sites like amazon.com and e.com, have led to the development of on-line disputes (Katsh et al., 1999). We argue that if a transaction occurs online, then disputants are likely to accept online techniques to resolve their disputes. Thus the development of e-commerce requires new ways of resolving conflicts. New ways of dispute resolution are hence appearing, so that the disputant parties neither need to travel nor to meet in courtrooms or in front of arbitrators or mediators. Different forms or methods of alternative dispute resolution for electronic environments have been pointed out by legal doctrine. As a result, we can now speak of Online Dispute Resolution (ODR) as any method of dispute resolution in which wholly or partially an open or closed network is used as a virtual location to solve a dispute (Katsh \& Rifkin, 2001).

A relevant issue, in a quick look, will be to inquire in what way (and to what point) traditional mechanisms such as negotiation (Raifa, 2002), mediation (Brown \& Marriott, 1999) or arbitration (Bennett, 2002) can be transplanted or adapted to the new telematic environments, taking advantage of all the resources made available by the newest information and communication technologies. In order to develop intelligent and efficient techniques to support Online Dispute Resolution, one needs to integrate Artificial Intelligence based problem solving techniques with Online Dispute Resolution ones. This information can be considered from two different perspectives: on the one hand, as a tool to help the parties and the decision makers to obtain the best possible results in solving commercial disputes and, on the other hand, considering a new way of autonomous dispute resolution through the use of autonomous and intelligent software, supported by a knowledge base and decision capabilities. Thus, it will be important to consider the many alternatives for dispute resolution that arise from Artificial Intelligence models and techniques (e.g., Argumentation, Game Theory, Heuristics, Intelligent Agents and Group Decision Systems) as described in Peruginelli \& Chiti (2002) and Lodder \& Thiessen (2003).

Contrary to previous approaches, in Online Dispute Resolution it must be considered not just the disputant parties and the eventual third party (mediator, conciliator, arbitrator) but also what Ethan Katsh and Janet Rifkin call "The fourth party", i.e., the technological elements involved. An 
important element of this "fourth party" will obviously be the emergence of expert systems and intelligent software agents empowered to help the parties and the mediator/arbitrator in reaching a fair solution. And as (Lodder, 2006) already refers, it must be considered as well a "fifth party", i.e., the service providers, those who provide and deliver the technological elements. All this is turning ODR in a quite new and somewhat complex (but eventually quite fast, cheap and advantageous) way of interaction and of solving conflicts.

The goal of AI research in this field is to attain a technological threshold, resulting in computational systems that are indeed the 3rd party. In this sweeping approach, there is no human intervention on the outcome or in guiding the parties to a specific situation. There is, on the other hand, a system that performs that major role. This is usually known as an electronic mediator or arbitrator. It should have skills for communicating with the parties and understanding their desires and fears and have the ability to decide on the best strategy to be followed in each possible scenario. This is evidently the most challenging approach to follow since it is not easy to implement in a computer system the cognitive abilities of a human expert, as well as the ability to perceive the emotions and desires of the parties involved. On the other hand, there is an inherent risk in letting machines take binding decisions that influence our lives (Lodder and Zeleznikow, 2010).

ODR systems can be categorized according to the function that machinery may play (Peruginelli, 2002). First generation ODR systems describe the systems that are used in our moment in time. The main idea behind these systems is that the human beings remain the central pieces in the planning and decision making processes. Computational tools are evidently used, but they are seen as no more than equipment, without any autonomy or a major role in the course of action. In this kind of ODR systems the main technologies used are instant messaging, forums, video and phone calls, video conference, mailing lists, and more recently, Video Presence. Agentbased technologies may be used but have no active part or autonomy. These systems are common nowadays and are usually supported by a web page. They represent a first necessary step before the consideration of those that may be more autonomous, a characteristic that may be achieved through the use of intelligent systems.

The second generation of ODR systems is essentially defined by a more effective use of technical tools. It is no longer used for the mere job of putting the parties into contact and/or making access to information easier. It goes beyond that and it is used for idea generation, planning, strategy definition and decision making. In that sense, it can be said that second generation systems extends its first generation with new intelligent and autonomous artefacts. This new generation relies and is supported by technologies that allow for a regular connectivity among all the entities involved. However, by using innovative technologies on top of this communication layer, it is possible to present services with more added value. For the implementation of such services, one can look at fields as diverse as Artificial Intelligence, Mathematics or Philosophy. In the intersection of these fields one can find a range of technologies that will significantly empower the previous generation of ODR tools, namely artificial neural networks, intelligent software agents, case-based reasoning mechanisms, methods for knowledge representation and reasoning, argumentation, learning, and negotiation. Thus, we move forward from a paradigm in which reactive communication tools are used by parties to share information, to a virtual environment in which ODR services proactively assist the disputant parties.

Therefore, it is clear that the involvement of different areas of research, namely the one of Artificial Intelligence, may contribute to develop ODR processes that will deal with other sorts of problems, namely complex multiparty, multi-issue, and multi-contract ones. Using such technologies will be also easier to develop processes that mimic the cognitive processes of human experts, leading to more efficient ODR tools.

In Table 1 we describe a number of commercially available ODR providers in the area of The Law. A previous survey by Melissa Tyler exists, conducted in 2004, in which 115 ODR sites were identified (Tyler, 2004). In that sense, we do not include here an extensive list of sites. Instead, the most important ODR providers were selected, in order to compile a list that can show the wide range of fields in which ODR tools can be used. Moreover, we also add several new sites that were identified in the meantime. In this compilation, the isolated use of certain telematics means, such as video-conferencing, is not regarded as an advantage. As an example, there are systems that claim to allow videoconferencing between the parties, although in reality the system simply arranges the meeting and parties must use external traditional videoconference mechanisms. 
However, systems that create virtual environments in which such telematic means are embedded and are used seamlessly by parties are valued here.

Table 1. A compilation of some major ODR service providers and resources.

\begin{tabular}{|c|c|c|c|c|c|c|c|c|c|}
\hline & $\mathbf{I}$ & $\mathbf{S}$ & $\mathbf{T}$ & & & & & Core & Usability \\
\hline & & & & C & $\mathbf{N}$ & $\mathbf{M}$ & $\mathbf{A}$ & & \\
\hline ANDRC & $\mathrm{X}$ & $\mathrm{X}$ & $\mathrm{x}$ & $\mathrm{X}$ & $\mathrm{X}$ & $\mathrm{x}$ & $\mathrm{X}$ & $\mathrm{HE}$ & - \\
\hline ARyME & $\mathrm{x}$ & & & & & $\mathrm{x}$ & $\mathrm{x}$ & WP & - \\
\hline BBB & $\mathrm{X}$ & & $\mathrm{x}$ & $\mathrm{x}$ & & $\mathrm{x}$ & $\mathrm{x}$ & $\mathrm{HE}$ & - \\
\hline $\begin{array}{l}\text { Peruvian } \\
\text { Cybertribunal }\end{array}$ & & $\mathrm{X}$ & & $\mathrm{X}$ & & & $\mathrm{X}$ & WP, HE & Web forms \\
\hline CPR & $\mathrm{x}$ & & $\mathrm{x}$ & & & $\mathrm{x}$ & $\mathrm{x}$ & WP, HE & - \\
\hline CyberLaws.net & $\mathrm{x}$ & & & & & & & WP & - \\
\hline $\begin{array}{l}\text { Electronic } \\
\text { Courthouse }\end{array}$ & & $\mathrm{X}$ & $\mathrm{x}$ & & & $\mathrm{x}$ & $\mathrm{x}$ & $\begin{array}{l}\text { WP, information } \\
\text { management tools, } \\
\text { virtual workrooms, } \\
\text { settlement } \\
\text { conferences }\end{array}$ & $\begin{array}{l}\text { Web forms, } \\
\text { Automatic update of } \\
\text { information, } \\
\text { notifications }\end{array}$ \\
\hline Eucon & $\mathrm{x}$ & $\mathrm{x}$ & & & & $\mathrm{x}$ & & $\mathrm{HE}$ & - \\
\hline ICC & & $\mathrm{x}$ & & & & $\mathrm{x}$ & & $\mathrm{HE}$ & - \\
\hline JAMS & & $\mathrm{x}$ & & & & $\mathrm{x}$ & $\mathrm{x}$ & $\mathrm{HE}$ & - \\
\hline Mediation Now & $\mathrm{x}$ & $\mathrm{X}$ & & & & $\mathrm{x}$ & & WP & - \\
\hline Mediation Room & & $\mathrm{X}$ & $\mathrm{x}$ & & & $\mathrm{x}$ & & $\begin{array}{l}\text { WP, HE, single } \\
\text { platform for unified } \\
\text { information } \\
\text { management }\end{array}$ & $\begin{array}{l}\text { Web forms, } \\
\text { privileged access to } \\
\text { information } \\
\text { according to roles, } \\
\text { tailoring of sites to } \\
\text { specific clients }\end{array}$ \\
\hline Forrest Mosten & $\mathrm{X}$ & $\mathrm{x}$ & $\mathrm{X}$ & & & $\mathrm{x}$ & & $\mathrm{HE}$ & - \\
\hline ODRWorld & & $\mathrm{x}$ & & & $\mathrm{X}$ & $\mathrm{x}$ & $\mathrm{X}$ & WP, HE & $\begin{array}{l}\text { Web forms, Message } \\
\text { board, online chat }\end{array}$ \\
\hline Private Judge & & $\mathrm{x}$ & & & & $\mathrm{x}$ & $\mathrm{x}$ & $\mathrm{HE}$ & - \\
\hline Resolution F. & & $\mathrm{x}$ & $\mathrm{x}$ & & & $\mathrm{x}$ & $\mathrm{x}$ & $\begin{array}{l}\text { WP, HE, virtual } \\
\text { break-out rooms }\end{array}$ & $\begin{array}{l}\text { Simple text-based } \\
\text { conferencing system, } \\
\text { session transcript }\end{array}$ \\
\hline Settle the Case* & & $\mathrm{x}$ & & & & $\mathrm{x}$ & $\mathrm{x}$ & WP, HE & - \\
\hline SmartSettle & $\mathrm{x}$ & $\mathrm{x}$ & $\mathrm{X}$ & & $\mathrm{X}$ & & & $\begin{array}{l}\text { Flash WP, } \\
\text { optimization } \\
\text { algorithms, unified } \\
\text { case manager }\end{array}$ & $\begin{array}{l}\text { Intuitive interface, } \\
\text { quantitative and } \\
\text { qualitative analysis } \\
\text { tools }\end{array}$ \\
\hline TRUSTe & $\mathrm{X}$ & $\mathrm{x}$ & & & & $\mathrm{x}$ & & WP & Web forms \\
\hline WIPO & & $\mathrm{x}$ & & & & $\mathrm{x}$ & $\mathrm{x}$ & $\mathrm{HE}$ & E-mail filing \\
\hline Camera Milano & $\mathrm{x}$ & $\mathrm{x}$ & & & & $\mathrm{x}$ & $\mathrm{x}$ & $\mathrm{HE}$ & E-mail filing \\
\hline OAN & & $\mathrm{x}$ & & & & & $\mathrm{x}$ & $\mathrm{HE}$ & - \\
\hline V. Courthouse & & $\mathrm{x}$ & & & & $\mathrm{x}$ & $\mathrm{x}$ & HE, Flash WP & $\begin{array}{l}\text { Intuitive interface, } \\
\text { web forms }\end{array}$ \\
\hline Arbitrare & & $\mathrm{x}$ & & & & & $\mathrm{X}$ & HE, Flash WP & $\begin{array}{l}\text { Intuitive interface, } \\
\text { web forms }\end{array}$ \\
\hline
\end{tabular}

* This site appears to be inactive since year 2000.

I: A web-site that provides valuable information about ODR.

S: A web-site that directly or indirectly (e.g. by containing a list of mediators or arbitrators) provides ODR services.

T: A web-site that provides training for either parties or neutrals on the field of ODR.

Resolution Modes: The several resolution modes that a web site deals with, either in the form of the actual provision of services or simply the categories that the available information refers to. 
C: Conciliation - the neutral meets with the parties separately, hears them, and tries to solve their differences.

$\mathbf{N}$ : Negotiation - the parties dialogue and expose their interests in order to achieve an agreement.

M: Mediation - the neutral tries to guide the discussion in a way that optimizes the parties needs.

A: Arbitration - the neutral meets the parties and produces an Award that may or may not be enforceable.

HE: systems that rely significantly on Human Experts including Solicitors, Arbitrators, Attorneys, Judges, among others.

WP: Systems in which the web page plays a central role.

Core: the elements under this category describe the core of the system, i.e., the key resource or resources that support the system.

Usability: this category describes the main points of each system regarding the usability, i.e., what are the tools or approaches available for the users to interact with the system.

\section{Artificial Intelligence in Online Dispute Resolution}

AI research has led to the development of many technologies that are nowadays in intense use, most of the times in the shadow of big systems. These technologies are generally used to optimize knowledge-based processes, to make products easier to use with the adoption of intelligent interfaces or to automate tasks. Among the main problems addressed by AI research, one may look at the new methodologies for problem solving, to the challenges put to us in terms of knowledge representation and reasoning procedures, planning, learning, natural language processing, motion and manipulation, perception, social and evolutionary intelligence, feelings or creativity. These techniques can be applied in a wide range of domains, including medicine, weather forecast, finance, transportation, games, aviation or The Law. In the particular case of the legal domain, the application of AI techniques is not new and represents an opportunity for both fields.

In fact, the first automated systems developed for the legal arena consisted of purely logical systems that were relatively complex to use and very domain-specific. Therefore, only a limited number of trained specialists could use them. At this point, there was the need to develop applications that could make use of these logical tools in a broader way. According to Oskamp, (Oskamp et al., 1995) researchers should aim at the development of practical and intuitive applications that could be used by non-experts. It is our conviction that the best path to achieve such applications consists in the integration of concepts from AI and The Law in order to develop ODR platforms that can efficiently address the challenges that the legal domain is currently facing.

\subsection{How can Artificial Intelligence Improve ODR}

It is a fact that computers are being intensively used in virtually every domain and the legal one is not an exception. However, the functionalities and the possibilities of computers are not being fully exploited, being relegated to basic back office tasks such as text processing, billing, agenda management, communication, among others. Nevertheless, the role that technology plays in this field will slowly begin to change as AI techniques develop. Historically, the beginning of AI \& The Law research can be assigned to Bruce Buchanan and Thomas Headrick when, in 1970, they published the paper Some Speculation About Artificial Intelligence and Legal Reasoning. In the interim, research in this field began to increase, with the appearance of some international conferences, associations and journals, revealing the growing interest of the scientific community for this area. In this section we will examine some of the branches of AI research and determine how each one can be used to improve our knowledge about the legal domain and, specifically, the current dispute resolution processes. Table 2 highlights the major features of each of the technologies here presented.

\section{Decision Support Systems}

With the constant growth of the amount of information present in the decision processes, the need for tools that could provide support has also grown. Indeed, the new economy, along with 
increased competition in today's complex business environments, takes the companies to seek complementarities in order to increase their competitiveness and reduce risks (Bonczek et al., 1981). Under this scenario, planning takes a major role in a company's life. However, effective planning depends on the generation and analysis of ideas (innovative or not) and, for this reason, the idea generation and management processes become a crucial tool in present days. The tools used may range from simple systems for compiling useful information from raw data, to more complex ones that make suggestions on the best strategy to be used or the fairest outcome.

Decision support systems may be used in virtually any knowledge based environment and the legal domain is not an exception (Turban, 1993). In the legal arena, these are known as legal decision support systems. However, as its use is still recent, there are not any advanced implemented systems. Nevertheless, the ones that have been developed so far have something in common (Zeleznikow and Hunter, 1994): they are rule-based. There are several reasons for this: rule-based systems are generally easy to understand and implement, there are a lot of tools for building rule-based systems and many legal concepts can be modeled using rules. These rules are instructions of the type IF condition THEN conclusion, that is, if certain conditions are verified, one or more conclusions will be true.

Considering the complexity of the legal domain, legal decision support systems can be quite useful, specifically if one considers the huge amount of information that parties and neutrals must analyze in certain complex cases in order to take decisions. Without using any supporting tools, analyzing all this information is an inefficient process that consumes much time, slowing down the legal processes. Moreover, there are parties that may not be at ease with certain kinds of information, having trouble to take right decisions.

These systems thus have the ability to analyze relevant facts input by the parties as well as legal information such as norms or past known cases in order to make simple legal decisions. There are some fields in which decision support systems have been more significantly used. Social security systems use them to help practitioners deciding if an unemployed individual should or should not receive a benefit. Banks use them in order to more efficiently decide if a client should be granted a loan. As a last example, insurance companies use decision support systems when deciding on the amount of an indemnity to be paid to an insured. In any of these cases, as well as in the legal domain, results are generally supervised by human experts. Decision support systems are therefore not automated systems that issue outcomes. They are systems that, based on important information, issue justified recommendations and compile information that can be useful for the decision making process.

One example of application of decision support systems in the legal domain is Split Up (Zeleznikow \& Stranieri, 1995). This is an intelligent decision support system that makes predictions about the distribution of marital property following divorce in Australia. Its main purpose was to assist judges, registrars of the Family Court of Australia, mediators and lawyers. Split Up operates as a hybrid system, combining rule-based reasoning with neural network artifacts. A more recent example in the same legal domain can be found in (Brooke \& Zeleznikow, 2010), in which an agent-based negotiation decision support system for the Australian family law is presented.

\section{Expert Systems}

According to (Susskind, 1987), Expert Systems can be defined as computer programs that have been constructed in such a way that they are capable of functioning at the level of (and sometimes even at a higher standard than) human experts in given fields. In that sense, such systems are designed, trained and fine-tuned by humans and must embody a depth and richness of knowledge that allow them to perform at such level (Hayes-Roth, 1983). The training can be performed using information from past cases and respective decisions provided by human experts. On the other hand, these systems can also learn while they are used, generally with the supervision of an expert that makes adjustments according to the input, expected output and verified output. Similarly, Harmon \& King (1985) define Expert Systems as intelligent computer programs that use knowledge and inference procedures to solve problems that are difficult enough to require significant human expertise for their solution. Both definitions share one common idea: Expert Systems try to mimic the human expertise and knowledge in a given domain (Jackson, 1990). In that sense, it is correct to say that the knowledge necessary to perform such high level 
tasks as well as the inference procedures used can be seen as models of expertise of the best human experts in the field.

Expert Systems also represent a change in the programming paradigm (Forsyth, 1986). While traditional computer programs are seen as procedures applied to data, Expert Systems are seen as inference engines applied to knowledge. In that sense, the two new major modules are a rich knowledge base and a powerful inference engine. However, if we want to be more specific, four main components can be identified in a fully functional Expert System (Greinke, 1994): the knowledge acquisition module, the knowledge base, the inference engine and the user interface. In that sense, a fully functional Expert System is expected to be able to deal with information relating to a specific problem domain, analyse it and generate knowledge, and then take actions and decisions based on that knowledge. Given what has been said before, it is expected that these actions and decisions resemble the ones that a human practitioner would do in a similar scenario.

Expert systems can be found in a wide range of domains, including the fields of accounting, medicine, process control, financial service, production or human resources. There are several factors that lead to a growing use of this technology. On the one hand, Expert Systems can automate simpler tasks, releasing human experts to other higher level tasks or, eventually, allowing companies to reduce costs. On the other hand, the huge amount of information that practitioners in certain fields must deal with renders nearly impracticable a purely human workforce. This is also true in the specific case of the legal domain. In fact, legal practitioners can no longer deal with the increasing number of disputes and the information that each one requires, resulting in the well-known slowness in judicial systems. In that sense, Expert Systems can be a tool that helps legal practitioners dealing with huge amounts of information, automating the simpler tasks and, ultimately, allow them to work more efficiently.

On the whole, particularly constructive when considering the legal domain is the ability of an Expert System to detail the reasons for a specific analysis or recommendation, i.e., its ability to explain its actions. In order to do so, legal expert systems generally allow the assignment of weights to factual data on a case. This may trigger additional actions, such as comparing a given case to the cases stored in the knowledge base, producing outcomes based on similarity metrics. However, once again, these outcomes should be regarded as merely informational, i.e., legal expert systems should be used, for example, to help judges to deal more rapidly with the cases, providing guidance based on a model of the legal domain in question that includes the norms, the facts and past cases. Currently, complex Expert Systems of this level are not yet established. There are even authors that argue that these are not only difficult to implement but also unnecessary. Following this simplistic approach, James Popple (1996) presented SHYSTER, a simpler, pragmatic approach in which the utility of a legal expert system is evaluated by reference, not to the extent to which it simulates a lawyer's approach to a legal problem, but to the quality of its predictions and of its arguments. In fact, most of the legal expert systems currently at use are fairly simple implementations, focusing, for example, on automated drafting of complex legal documents. In such systems, users are generally guided through a series of interfaces with questions, while receiving practice tips or support about the legal domain or strategies. Nevertheless, other authors argue that a purely rule-based approach is inappropriate if the Expert System is to be of use to a lawyer. Popple (1991) concludes that a better approach is obtained when rule-based methods are combined with case-based ones.

\section{Knowledge-based Systems}

Knowledge is an abstract term that represents a collection of specialized facts, procedures, and judgment conventions. There are many types of knowledge and many different ways of acquiring it. First, knowledge can come from a single source or it can be compiled from several sources. Depending on the domain, it can be compiled from human experts (e.g. observing the behavior of a law practitioner), sensors (e.g. a domotic environment), pictures (e.g. medical imaging), maps (e.g. finding a path), flow diagrams or historic context, just to name a few. Depending on the type and source of information, several techniques for knowledge acquisition can be used, namely human observation, scanners, pattern matching, pattern recognition or intelligent agents.

Being the field of AI \& The Law a knowledge-based one, the subject of Knowledge Representation (KR), is a very important one. According to (Sowa, 2000), KR is a multidisciplinary subject that applies theories and techniques from three other fields: logic, ontology and computation. Logic provides structural formalisms and rules of inference. It is used 
for determining the validity of arguments, as well as their redundancy or contradiction, allowing for the test of the validity of a given outcome. Ontology defines the domain or context being dealt with, as well as the objects that subsist in the domain of discourse. Without ontologies, words have no meaning or value, are minimal sets of characters. Computation denotes the needed working out support for dealing with these questions on the processing systems sphere. Without this, KR would be an attitude problem as it has been until recently.

In a few words, KR is concerned with formalizing our way of thinking, i.e., how to represent a given domain with symbols. Considering the complexity of legal knowledge, the development of systems that are able to formally model knowledge is highly desirable (Brachman \& Levesque, 2004). These are the so-called Knowledge-based Systems.

Considering the legal domain, such systems are important, in a first stage, to define a model that can deal with a heterogeneous group of information. This group may include, but is not limited to parties' information, norms, past cases, facts or arguments. These systems are also essential when such information must be stored digitally in a way that allows for fast and efficient retrieval. When knowledge is stored in a formal and well-defined way, it allows for the development of automated processes that can, for example, interpret the validity of logic arguments. The development of systems that can efficiently cope with huge amounts of knowledge is in fact one important advance that legal practitioners can take advantage of, in order to deal with the current increasing number of disputes. Moreover, knowledge-based systems can be designed to deal with either statute law or case law (Popple, 1991). The main motivation behind the use of Knowledge-based Systems in the legal arena is its capability of representing norms and judgment under uncertainty. In fact, systems can be developed that can produce new facts or conclusions based on knowledge.

In general, several modules can be identified in a fully functional Knowledge-based System (in this case, six), namely the user interface that stands for itself; the explanation facility that details the inference mechanism that regulates the system outcome; the database with the factual information; an inference that decides on which rules are to enforce, and how they are prioritized; and, the knowledge acquisition module that is responsible for (possibly in an automatic way) the acquisition of knowledge from the outside world.

\section{Intelligent Interfaces}

Lawyers currently face a problem that has already been pointed out in this document, i.e., the ever growing amount of information that must be considered in legal problems, either in statute law or case law. On the one hand, in statute law, new statues and treaties are making its way, making legal analysis more complex. On the other hand, case law is faced with more and more disputes, which generate an exponential increase in legal rulings. The main reason for this happening is the process of socialization in course in terms of the use of information technology by the human beings, which not only adds to the information available but also increases the number and diversity of the disputes that must be solved.

Ironically, the same technologies that led to the exponential availability of information also show the way to the development of tools to deal with this information, i.e, technologies such as Expert Systems, Decision Support Systems or Knowledge-based Systems are now available that can assist practitioners. Nevertheless, the adoption of these useful tools has been rather slow, wasting the theoretical advantages. A possible cause for this drawback is pointed out by Matthijssen (1995), when the author states that in legal information systems the interfacemodalities do not shield the users of these systems from the internal organization of the data and the additional workload associated to the processing mechanisms, i.e., legal practitioners find a conceptual gap in this process, once they work in a given way, and legal information systems are either designed to work in a different way or are designed very closely to the internal structure of the system, providing no abstraction interpretation of the decision process.

This gap can be filled with the development of the so-called Intelligent Interfaces. Therefore, it will be useful for the developers to be aware of the way practitioners solve legal problems. Using this information, intelligent interfaces can be developed that reflect the knowledge domain of the practitioner rather than the structure of the stored data. The main objective here is that practitioners can focus on the actual content of the legal concepts rather than on how these concepts are translated and stored in legal information systems. Intelligent Interfaces are very singular, i.e., besides making the bridge between humans and computers, they present additional features. The 
eternal problem addressed, present on the legal domain (as well as in any knowledge-based domain), is in an efficient and effective retrieval of data (generally from a database). When the methods for retrieving information are much related to the structure of the data, it becomes harder for a non-expert to perform efficient searches. According to Matthijssen (1999), to a large extent, these problems can be attributed to the limitations of the traditional Boolean query mechanism used in text databases, which is difficult for users to operate. Using Intelligent Interfaces, it is possible to develop different forms of abstraction, at the user level, that make possible to personalize methods to access data, regardless its structure.

In order to implement this behavior, an intelligent interface needs specific data about the legal domain that is being addressed, as well as models for the representation of legal knowledge, its rules and processes. Additionally, such interfaces can also take into consideration personal preferences or user roles. Then, it can act as an intelligent intermediary between the user and the database. Using such an interface, practitioners can make use of a more intuitive and powerful tool to analyze and organize information. Possible applications include the structured publication of high amounts of information, automated organization of data according to a given criteria or automated search. Another interesting area of application is one in which the user is not completely sure of how to search or what to search. A search request may be incomplete, incorrect or inaccurate and the interface is responsible for assisting the user in reformulating the request or trying to guess what the user intentions are in terms of search. In order to fulfill these goals, the interface must be adaptive, anticipate the needs of the user, proactive and able to explain its actions. We can also think of search engines like Google or Yahoo as intelligent interfaces. In fact, they often do successful searches although we misspell the search terms, or suggest similar words or concepts in order to make our search more accurate. Intelligent Interfaces also filter the information, deciding which is closer to what the user is looking for and which is useless. In order to do this, context information is taken into account (e.g. legal domain, past experiences, domain of expertise of the practitioner). One particular case of application of Intelligent Interfaces in the legal domain is the one of the intelligent tutors, aimed at teaching or training its users in a given area (e.g. LITES, an intelligent tutoring system for legal problem solving in the domain of Dutch Civil law, (Span, 1993) and (Ashley \& Aleven, 1991), where an intelligent tutoring system for teaching law students to argue with cases is described).

\section{Case-Based Reasoning}

Case-based Reasoning (CBR) can be described as a problem solving methodology that relies on past experiences and its data to make present choices (Kolodner, 1992), (Aamodt and Plaza, 1994). The key assumption is that if a new problem is similar to an old one, it will have a similar outcome. This procedure is commonly observed in humans and is intrinsically related with our learning processes. As an example, let us consider that some time ago, an individual left home, with a cloudy sky, and the clouds turn into rain, and he/she got wet. A few days later, before leaving its house, the same individual look at the sky and, as it is was cloudy, took an umbrella with him/her. In general, this process involves the ability to compare two scenarios (or cases) and admit that if they are similar, they will have an identical outcome. Consequently, the first task is to select among all the uniqueness that describe a case, which are the ones that are useful to determine the similarity between two cases. Failing to do so will lead to the impossibility of dealing with all the attributes that define a given universe of discourse and their range of possible values. Continuing with the previous example, the individual could take the decision of taking or not taking an umbrella based on different factors: the day of the weak, the weather forecast, the current weather conditions, the clothes wore and/or the distance to the local of destination. While some of these factors make sense (e.g. the current weather conditions, the weather forecast) considering the nature of the problem, others are completely irrelevant. The first challenge is therefore to select which attributes to consider, according to the problem domain (or universe of discourse).

It is also essential to enquire the relative significance of each of the problem attributes. In our previous example, it makes sense to consider both the current weather conditions and the weather forecast. However, a different weight might be given to the weather forecast attribute if the individual is more worried about the evolution of the weather conditions and not so much concerning the immediate ones. This factor may however be different, depending, for example, on the hour the individual will be outside or its confidence on the weather forecast. 
Generally, a CBR process is organized in four sequential phases: Retrieve, Reuse, Revise and Retain (Kolodner, 1993). In the first phase, the problem is analyzed and the cases that are relevant (i.e. similar enough) are retrieved from the memory, possible ordered according to a value of similarity. This measure of similarity depends on the problem domain but generally consist of on a difference of the sums of the different attributes that characterize the cases. In the Reuse phase, the solution from the previous case is mapped to the target problem, which may involve adapting the solution to some specific requirement of the new problem. This phase is necessary since, in general, there is no case in the case memory that exactly matches the attributes of the new case. In theory, it would be possible to generate as many cases as needed to cover all the different attributes. However, the size of such a case base would be impracticable. There is, hence, an implicit compromise between the amount of cases stored and the values of similarity achieved. In the third phase, the solution is tested or simulated in an attempt to determine the result of its application. It may be possible that the results are not good as expected, which should conduct to the revision of the action taken. In the last phase, the solution adopted may be stored in the case memory, along with the description of the new case, contributing to the enrichment of the case memory.

CBR is obviously suitable to be used in the legal domain, once the ability to predict or estimate an outcome is an important component of legal advice. A legal practitioner frequently examines past similar cases and their outcomes to try to predict the outcome of a new case. There is even a similar legal concept: the legal precedent (Landes \& Posner, 1976). The notion of legal precedence defines a case that establishes a rule or principle that could or should be utilized by practitioners when deciding on subsequent similar cases. CBR models are, in principle, particularly useful in common law systems, in which The Law is interpreted and applied by judges. Nevertheless, civil law systems (in which The Law is written by a legislature's enactment (Zweigert \& Kötz, 1998)) can also be approached from a case-based perspective, namely through the development of systems that target the retrieval of information with the objective of informing the users instead of producing outcomes. Considering this topic, Ashley poses the question: "should researchers in a civil law jurisdiction pursue work on implementing AI \& The Law models of case-based legal reasoning in a civil law context?" He answers with a conclusive "the answer may well be, "Yes"!" (Ashley, 2004).

Although being object of research, CBR is already one of the most commonly used approaches in the development of intelligent and learning systems, for the most varied purposes. (Watson, 1997) gives some examples of big enterprises like air and fraud management companies where the use CBR is routine. Likewise, the legal field has some implementations of CBR that address specific problems. HYPO models the way attorneys argue when confronted with a case, real and hypothetical (Ashley, 1991). CATO is an intelligent learning environment, designed to help law students to learn the basic skills of argument building when leading with a case (Aleven, 1997). More recently, Brüninghaus \& Ashley (2003) presented IBP. The Issue-Based Prediction algorithm combines a logical representation of subjects or matters with a case-based reasoning component for predicting and explaining the case outcomes.

\section{Multi-agent Systems}

Multi-agent Systems (MAS) (Wooldrige, 2002) emerged from the combination of Artificial Intelligence based methodologies and techniques for problem solving with distributed computational models, generating a new area of research: Distributed Artificial Intelligence. It were purposed different definitions for a MAS, so we will try to define it from a legal point of view. A MAS is a group of entities (software or hardware) that make intelligent decisions in order to achieve some common goal (like proposing a solution for the parties in dispute) based on information that is shared among every agent in the system. Parunak (1997) proposes a detailed definition, based on the presupposition that a MAS is not only defined by the agents or their properties, a MAS is defined by a triple, i.e., a set of agents, an environment and a pairing between them. We have to agree with Parunak since an agent is genuinely associated with the environment, as its actions depend on the state of its peers. As an analogy, we humans commonly look to ourselves in function of our social or geographical positioning, i.e., our environment and our social relations make us who we are.

Agents materialize an appealing computational tool as they allow for a wide range of behaviours and/or functionalities to be analysed, specified and/or implemented. In particular, there 
is a set of assets proposed by (Wooldridge \& Jennings, 1995) that make what the authors call the weak notion of agent, i.e., autonomy, social ability, reactivity and pro-activeness. This vision entails that the most basic agent should, at least: (1) operate without the direct intervention of humans and formulate its own decisions in an autonomous way; (2) be able of interacting with other agents (independently of their nature); (3) perceiving the environment and responding on time to the stimuli and; (4) take the initiative of pursuing its goals. The same authors also proposed a stronger notion of agent that may include properties such as mobility, veracity, benevolence or rationality. This means that additionally, an agent may move between locations by means of a network, will not give false information on purpose, will not have conflicting goals and always will try to do what is asked for (an agent will always act in order to achieve its goals).

The main objective of the present approach to computing is to address the complexity of intelligent behaviour intra and inter communities of simple entities or agents (Olson et al., 2001), i.e., agents must be able to autonomously make their undemanding assessments that, once combined, may lead the communities of agents to perceive intelligent behaviour. This approach has nowadays a major role in the design of intelligent systems. Especially interesting for the legal domain is the research on argumentation theory. In argumentation, agents debate, defend their beliefs and try to convince their peers of the rationality of their causes (Rahwan, 2009). There is here an evident parallelism with the argumentation procedures that take place during dispute resolution processes. Agents may also implement negotiation techniques (Beer et al., 1999).

In the context of a MAS, negotiation refers to the modelling of human conciliation techniques so that they can be used for solving conflicts between agents. The main field of application of this modus operandi is in conflicts that arise from auctions and e-Commerce. In this specific sub-field of dispute resolution, agents may represent the parties in a negotiated settlement and try by themselves to get to an end, then suggesting it to the parts in dispute. An important analogy may also be done with negotiation procedures that take place in the legal arena, between parties that are trying to achieve a common agreement. The use of MAS in the legal domain is just right. A different kind of add value that comes with the use of MAS, from which the legal domain may profit, is distributed problem solving. Significant virtues in the legal domain (e.g. veracity, benevolence) can also be instilled into agents, namely in the so-called emotion-based ones (Velasquez, 1997). In the legal field, this kind of work may lead to the implementation of the second generation of ODR systems, with the ability to understand the feelings of the parties according to each topic of the dispute.

\section{Legal Ontologies}

In philosophy, ontology is the study of the nature of existence in general. In that sense, ontology deals with the questions that concern the definition of a given entity, its existence, and how that entity relates with others. In computer science, ontologies are a way of formally representing knowledge in terms of concepts within a domain and the relationships between those concepts. According to (Gruber, 1993), an ontology is a "formal, explicit specification of a shared conceptualisation". In order for the ontology to be understood, a shared vocabulary must be provided. This vocabulary must contain all the concepts that can be used to model the domain of discourse, i.e., the ontology must define the type of each concept as well as their properties and relations. Therefore, in ontology specification, one defines classes and subclasses of individuals as well as the properties of each individual in a class or subclass. If on top of that are also defined relationships between individuals, it will be possible to infer properties, namely by inheritance.

In computer science, ontologies are nowadays paramount, mainly because they are the enablers of the so-called Semantic Web. The Semantic Web describes a group of methods and technologies that allow machines to understand the meaning of information on the Web, rather than simply accessing it. That is indeed the main innovation that ontologies brought along, i.e., allow machines to read, interpret and understand information. Logically, such technologies can also be used in other domains than the Web. Specially, ontology's are used in different systems, ranging from software engineering, biomedical informatics, library science, and information architecture, among others.

Indeed, for complex domains, like the legal one, the advantages are considerable. For instance, by systematizing knowledge, it becomes readily available. It allows not only for the extraction of rich patterns of information that otherwise would not be perceptible, but also to draw inferences. Indeed, computer models that can efficiently deal with huge amounts of structured information are 
being object of research, namely by Corcho et al. (2005), that presents a methodology to build an ontology in the legal domain following the development method METHONTOLOGY, and using the ontology engineering workbench WebODE; Visser and Bench-Capon (1998) that presents, compares and critiques four different legal ontologies. For more interesting examples on legal ontologies, the book "Law and the Semantic Web" presents a selection of revised papers drawn from two meetings devoted to the Semantic Web and the legal domain: The International Workshop on Legal Ontologies and Web-Based Legal Information Management (Benjamins et al., 2005).

\section{Rule-based Systems}

Rule-based Systems (RbS) are, in general, the straightforward way of implementing a system intelligent behaviour, i.e., they stand for the simplest form of building Artificial Intelligent systems. Using a RbS, it is possible to encode the knowledge and skill of a human expert in a given domain in the form of IF-THEN rules, in which each rule denotes a small piece of the expert's knowledge. Rules have a left and a right hand side. On the left side there is information about facts that must be true in order for the rule to be enforced. On the right hand side, the rule contains the actions that should be carried out whenever the rule is fired. The model of execution of a $\mathrm{RbS}$ consists, therefore, in analysing, on the fly, the left hand side of all rules. The rules whose left hand side is evaluated to true are placed on an execution agenda. Then, rules in the agenda will be executed, without any explicit order, and then removed from the agenda. One singularity of $\mathrm{RbS}$, contrasting with standard object-oriented programming, is that there is not an effecting order that can be predicted beforehand.

Thus, $\mathrm{RbS}$ are a way to store, interpret and manipulate knowledge about a given domain. In fact, if appropriate design strategies are followed, these systems allow for an ease access to an expert knowledge, i.e., whenever knowledge about the domain changes, only specific rules need to be transformed. This can be even looser if a proper and perceptive rule editor is made available and used by non-experts. In order to have a fully operational RbS, a rule engine is necessary, which stands for it.

If we consider specifically the legal domain, a parallel can be established between the legal corpus and other legal conceptions that may be expressed as RbS. The most obvious one is that when capturing the expertise of an expert in a given field, that expertise will become available to all. However, when representing legal rules in a $\mathrm{RbS}$, some issues must be kept in mind in order to avoid some possible problems. Indeed, if one tries to encode considerable amounts of knowledge into a single $\mathrm{RbS}$, the system may become inefficient, once it must search through a very large number of rules. Another possible disadvantage is that rules may not exactly implement the reasoning process used by an expert as no specific execution sequence can be dictated. Last but not the least, is related with the open textured nature of The Law and reasoning mechanisms being used (Popple, 1991). In fact, when a judge decides on verdicts, he/she does not look only at the rules that apply in that situation. There is more information that influences the outcome, such as recurrence or intention of the defendant, information that is hard to model in such systems.

Nevertheless, RbS are broadly used in different areas of doings, namely in insurance companies, banks, fraud detection, e-commerce and evidently in The Law. In conclusion, these systems implement a fairly simple and efficient way of modelling knowledge and expertise of a human practitioner in a well-defined field. Such systems can be particularly useful in the legal domain, once this field is rather rule-based, i.e., legal practitioners are usually confortable about using such systems as they reflect their way of reasoning.

Table 2. The most interesting features of several sub-fields of Artificial Intelligence from the conflict resolution point of view.

\begin{tabular}{|l|l|}
\hline Technology & Major Features \\
\hline DSS & $\begin{array}{l}\text { Compile and provide useful information } \\
\text { Provide support for decision processes } \\
\text { Propose actions based on the analysis of facts }\end{array}$ \\
\hline ES & $\begin{array}{l}\text { Model human knowledge and inference mechanisms } \\
\text { Reason similarly to human experts } \\
\text { Automation of "simple" tasks by applying an inference engine to knowledge }\end{array}$ \\
\hline
\end{tabular}




\begin{tabular}{|l|l|}
\hline KBS & $\begin{array}{l}\text { Model complex knowledge } \\
\text { Represent norms and judgment under uncertainty }\end{array}$ \\
\hline II & $\begin{array}{l}\text { Build a layer of abstraction for complex systems } \\
\text { Faster, intuitive and more efficient access to information }\end{array}$ \\
\hline CBR & $\begin{array}{l}\text { Reasoning processes similar to the legal ones } \\
\text { Contextualized retrieval of information } \\
\text { Information is organized according to meaningful attributes }\end{array}$ \\
\hline MAS & $\begin{array}{l}\text { Distributed problem solving } \\
\text { Implement negotiation protocols } \\
\text { Support for argumentation }\end{array}$ \\
\hline Ontologies & $\begin{array}{l}\text { Representation of legal knowledge } \\
\text { Inference } \\
\text { Pattern extraction }\end{array}$ \\
\hline RbS & $\begin{array}{l}\text { Encode knowledge, expertise and processes of human experts } \\
\text { Fairly simple way of interpreting and reasoning with rules }\end{array}$ \\
\hline
\end{tabular}

\subsection{Projects on the Intersection of AI and Law}

Now, we will consider the role that Artificial Intelligence (AI) based techniques may play in the development of better ODR tools, once such practices may be used with the objective of emulating the behavior of human experts in a given field. We would do that by looking to a set of projects of reference depicted below.

\section{Rule-based Legal Decision-making Systems (LDS)}

This work dated from the eighties and was one of the first decision support systems to be developed (Waterman \& Peterson, 1980) in the domain of liability law, which holds responsible product distributors and manufacturers for the injuries their products may cause. The system created embodied the skills and knowledge of a human expert in the shape of antecedentconsequent rules. The project had as objective the capture of the decision-making processes of attorneys and claim adjusters involved in product liability litigation in the shape of rule-based systems, so that the effects that changes in legal doctrine have in settlement strategies and practices could be studied. The authors formalized the strict-liability concept on ROSIE language, so that the defendant could or could not be considered liable.

The knowledge embodied in the system was divided into different layers (in this case five), namely: the formal doctrine given in terms of rules that emerge from the legally responsible and common law; the informal principles depicted in terms of rules that are not explicitly expressed in The Law, but are generally agreed upon by legal practitioners; the strategies where the authors coded the methods used by legal practitioners to accomplish a given goal; the subjective considerations set in terms of rules that anticipate the subjective responses of people involved in the process; and last but not least, the secondary effects layer set in terms of meta-rules that describe the rules interactions at the object level. The authors concluded that despite the number of rules needed for given shape to The Law and the strategies to be followed in order to enforce it, the rule-based model was feasible and suited for this particular domain.

\section{EXPERTIUS}

EXPERTIUS is a decision-support system that advices Mexican judges and clerks upon the determination of whether the plaintiff is or not eligible for granting him/her a pension (on the basis of the "feeding obligation"), and if so upon the determination of the amount of that pension (Cáceres, 2008). The system comprises three main modules: a tutorial, an inferential, and a financial module. The tutorial module guides the user through the accomplishment of quite a lot of tasks. The inferential module evaluates evidence based on weights that the user assigns to each piece of evidence. It determines which presuppositions are defeated and which prevail. Last but not the least, the financial module assists the user on the calculus of the pension values.

Expert knowledge is stated in terms of 3 (three) interrelated layers: a former one that stands for the expert knowledge, an intermediate one that denotes the decisions regulated by the law 
procedures, and a third one that keeps up a correspondence between the dialogues written as conversation and measured in terms of a confrontation pattern, and the cases that arise as a result of the decisions taken at the intermediate level.

\section{SmartSettle}

Thiessen's SmartSettle stands for a decision support system that intends to find the middle ground among parties to settle disputes based on satisfaction functions acknowledged by them. Initially the parties declare to the system their tenure to each item under dispute, either using mathematical machinery and/or by sketching it. The assigned preferences are, however, not static as they may change during the negotiation process, resembling the adjustment of the first choices made by the parties. Besides assigning their preferences, the parties must decide on what would be a constructive outcome for each one and try to join it on a single text. On the one hand, during the negotiation process one may simply exchange messages, on the other hand SmartSettle may produce suggestions according to the current state of the case, which the parties may or may not accept. When the parties reach an impasse, they may ask SmartSettle for an equal distribution of the merchandise. It is important in this phase that the preferences are well defined once the allocation of items depends on that. A final document is then produced. All these chapters are supported by a web site on which the parties log in, access their personal data and perform all the actions related with the negotiation process. SmartSettle is based on the doctoral thesis of Ernest Thiessen (Thiessen, 1993). This work resulted in a commercial ODR, whose president \& CEO is Thiessen.

\section{Family_Winner}

The Family_Winner project is being developed by Zeleznikow and Bellucci and provides support on the Australian family law domain (Bellucci \& Zeleznikow, 2001). In order to attain this goal, the system uses game theory and heuristics (Zeleznikow \& Bellucci, 2004; Zeleznikow \& Bellucci, 2003), relying on an algorithm that is an adapted version of the AdjustedWinner (Brams \& Taylor, 1996) one. Working in the same way as in SmartSettle, the parties must provide as input to the system their tenure to each item under dispute, a value that denotes how much they hope for for each specific item under dispute. The system, according to these values tries to assign the items to the parties, having in mind that each allocated matter may change the preferences of the parties on the other issues.

Once this is done, the parties are asked whether they agree with the stuff distribution; if the answer is no, the system embarks on a negotiation of item-by-item, starting with the piece considered less controversial. The users are asked to rank the piece, so that it may be better distributed (Guasco \& Robinson, 2007), or "divide the pie" problems. These problems are characterized by a fixed number of items with an associated value that must be divided by the parts. This process of decomposition and division goes on until there are no more items under dispute.

\section{ALIS}

The Automated Legal Intelligent System (ALIS) stands for a decision support system that will provide European citizens and private companies with a transparent, fast, secure and reliable access to legal data in the field of intellectual property rights, in Europe. Our motivation in what concern this work is that the daily observation of legal systems in democratic countries or supranational institutions reveals severe problems of understanding, application and adhesion. There are different reasons for this. Firstly, there is a considerable increase in the number of laws and regulations that make it more difficult to comply with the applicable legal and regulatory framework. This complexity often generates repetitions, lacks, and contradictions within the system itself. Furthermore, legal professionals may be overwhelmed by simple cases requiring time and effort that could be better allocated to solve more complex issues that cannot be, still, dealt with only by technology. The ALIS system aims at solving these problems by providing tools for regulatory compliance, alternative dispute resolution, conflict prevention, support in law making and scientific and technologic developments. 


\section{PERSUADER}

PERSUADER (Sycara, 1993) is a framework for intelligent computer-supported conflict resolution through negotiation/mediation. The model integrates Artificial Intelligence and decision theoretic techniques to provide enhanced conflict resolution and negotiation support in group problem solving settings. This model has been implemented in the PERSUADER, a computer program which operates in the domain of labour management disputes. The main objective of PERSUADER is to act as a mediator, facilitating the disputants' problem solving so that a mutually agreed upon settlement can be achieved. The PERSUADER embodies a general negotiation model that handles multi-agent, multi-issue, singe or repeated encounters based on an integration of Case-Base Reasoning and Multi-Attribute Utility Theory.

\subsection{The current State of Artificial Intelligence and ODR}

Having analyzed some existing research projects and commercially available ODR providers, an assessment may be done about the shortcomings of the current state of the art in the ODR arena. If there is a conclusion that can be drawn, is that currently technology is not exploited as it could be. Indeed, there is a limited use of IT by legal practitioners that use it mostly to word processing, office automation, case management, and here at a rudimentary level, client and case databases or for electronic document interchange.

Some needs may, therefore, be pointed out. First of all, most of the existing ODR implementations rely on traditional forms for acquiring information, providing little to no assistance at all. Moreover, the visualization of information is done at a very low level, i.e., users see information in a way that is very close to how it is stored. This can indeed be pointed out as a major disadvantage as the lack of intelligent and intuitive interfaces can constitute a barrier for a wide acceptation and use of these systems. Technologies are also barely used for even the simplest forms of processes automation. This automation could boost the throughput of legal institutions and practitioners by automating simple tasks that do not explicitly need human intervention. Finally, another major drawback can be pointed out. It is a fact that very little systems use IT for knowledge management and goal achievement, i.e., the use of technologies able to handle complex models of legal information would improve information structuring and retrieval, improving the work of legal practitioners.

We conclude that IT still plays a secondary role on the ODR arena. In fact, the technologies that are more used are simply the ones required to implement traditional dispute resolution mechanisms over telecommunication systems. Consequently, current ODR systems have little to no autonomy at all and are barely automated. In a few words we can state that, excluding some innovative research projects, that first generation ODR systems are still the rule. A research effort must thus be conducted in order to achieve the so-called second generation ODR. The path to follow relies, in our opinion, in the use of intelligent techniques that can enhance ODR systems with conceptions such as autonomy and proactivity.

\subsection{The Future of Artificial Intelligence on Online Dispute Resolution}

Progress in the field of Artificial Intelligence (AI) and The Law has been slower than expected. In fact, in the excitement of the early years, it was expected that computers would soon have the skills and the computational power to take over the role of judges and attorneys. This is far from happening and, nowadays, this is not the main purpose of the work that is being pursued in this area. The main reason against sitting computers in the chairs of judges and attorneys, mainly uttered by lawyers, is that doing so is morally undesirable. However, that alone would not hold back the research being done in the area of AI and The Law; it would, at most, delay its implementation but not its development. One of the main reasons is that computers act as simple executors of rules while the legal field requires interpretation. While computers are unable to actually interpret norms and their framework, they will not be sufficient to make judicial systems. 
John Searle formalized this restriction on the well-known thought test of the Chinese Room (Searle, 1980):

"Suppose I am in a closed room and that people are passing in to me a series of cards written in Chinese, a language of which I have no knowledge; but I do possess rules for correlating one set of squiggles with another set of squiggles so that when I pass the appropriate card back out of the room it will look to a Chinese observer as if I am a genuine user of the Chinese language. But I am not; I simply do not understand Chinese; those squiggles remain just squiggles to me."

Moreover, law is not straightforward and ambiguous. That is, the interpretation of norms frequently raises doubts among legal practitioners, frequently leading to different and clashing interpretations and, consequently, different outcomes. Thus, at a first glance, one would conclude that we need a more specific definition of the norms, one that would lead to unambiguous interpretations. The problem is that the society is complex, with many conflicting values and norms of conduct. This task seems thus rather utopic. Nonetheless, let us admit that such achievement is possible, that we can define norms to the point that their interpretation is straightforward. It is evident that this would only be achieved by having a much higher amount of more specific norms. Would it be efficient to handle such a complex legal system? Would it be feasible to develop computer systems to handle such complexity?

Another challenge that future research in AI and The Law will face is related with the changing nature of the laws. Indeed, in civil law systems, the frequency of legislation changes is higher and higher. Moreover, as the number of cases solved by courts in common law systems increases, more and more different cases can be considered when solving a new one. Thus, another major challenge will be to deal with increasing and ever changing amount of information. From the technological point of view, for ODR systems that work in civil law domains (tendentiously rulebased), this means that whenever a legal norm changes someone will have to search the system for the rules or ontologies that implemented that norm and change them accordingly. Thus, there will be a growing effort to manage such systems and keeping them up to date without creating ambiguities. The same happens in common law domains, in which systems tend to be case-based. In these systems, the question is about whether a past case should or should not be considered after a clear trend of change in more recent cases. Here, there is also a growing effort to maintain a database of relevant information.

There are evidently many challenges to be addressed in the development of AI and The Law research. It is thus not clear if the development of fully autonomous software agents that can take the role of judges and attorneys will happen or not in a near future. Nevertheless, by aiming at that ambitious objective, researchers will continue to develop useful tools that will slowly but steadily improve the legal systems, making them more efficient and, ultimately, more accessible to people. And, in our opinion, this should be the goal of future AI and The Law research, i.e., not to develop highly advanced and complex systems that barely no one will use but to develop systems that can actually be used by individuals that have little to no knowledge at all about the legal field, essentially as support decision tools.

\section{Improving the Role of AI in Dispute Resolution}

Motivated by the acknowledged misuses of technology applied to The Law and, in particular, in the area of AI \& The Law, in 2006 it was started the TIARAC project - Telematics and Artificial Intelligence in Alternative Conflict Resolution. In this project we aim to improve the use of AI in The Law, so that more efficient and satisfactory conflict resolution methods can be developed. For this purpose, a conflict resolution framework designated UMCourt is being developed in which we are applying and assessing the results of our research. Among others, two main issues are being addressed, i.e., the development of contextualized knowledge retrieval methods and the development of dynamic negotiation and mediation processes. These two lines of work are described below. 


\subsection{Knowledge Retrieval}

The main objective of this line of work is to develop methods that are able to retrieve structured information for the parties in dispute, so that they may mature on better policies and take more informed decisions. The information considered in each case is synthetized in Table 3. Our approach is clearly a hybrid one in the sense that we seek to mix the completeness and adaptivity of case-based reasoning methods for problem solving with the efficiency and simplicity of rules that aim at the same goal. Indeed, we are developing diverse methodologies for problem solving that may be dynamically chosen and combined by ODR systems according to the preferred attributes and accomplishment desired. Our approach is a threaded one, i.e., we start by using lightweight algorithms for pre-selecting cases, then we evaluate algorithms to organize the cases according to a given criteria, which finally leads to the generation of constructive data or knowledge.

Table 3. The structure of a case

\begin{tabular}{|c|c|c|}
\hline Cat & Info Type & Description \\
\hline \multirow{4}{*}{$\frac{E}{\frac{1}{0}}$} & Background & $\begin{array}{l}\text { Basic information about the parties and the dispute such as } \\
\text { party's personal information and location, dispute starting date, } \\
\text { witnesses. }\end{array}$ \\
\hline & Objectives & $\begin{array}{l}\text { A list of the initial objectives of each party towards the dispute, } \\
\text { the intended outcome. }\end{array}$ \\
\hline & Legal & $\begin{array}{l}\text { Legal information such as the norms used by the parties and } \\
\text { witnesses to support their claims or the guilty statement. }\end{array}$ \\
\hline & Dates & All the important dates of the case. \\
\hline 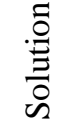 & List of actions & $\begin{array}{l}\text { A list of the actions performed by the parties in order to achieve } \\
\text { the outcome. Generally, these actions comprise trade-offs. }\end{array}$ \\
\hline \multirow{2}{*}{ 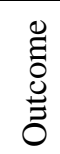 } & Outcome description & A list of actions that describe the outcome. \\
\hline & Value & $\begin{array}{l}\text { A value denoting the percentage of successful applications of } \\
\text { this case in the dispute resolution process }\end{array}$ \\
\hline
\end{tabular}

\section{Pre-selection}

The aim of the pre-selection phase is to efficiently make a selection of candidate cases that may be appropriate to address a given problem. The main concern here is to narrow the search space, so that the evaluation algorithms may do it faster. Under this line of attack, the evaluation algorithms are only applied to the pre-selected cases rather than to all the cases in the case-base, i.e., the preselected cases are somehow relevant. As an example, a case that addresses legal norms different from the ones addressed by the case currently being dealt with, should not be pre-selected as it probably addresses a different issue. Such beliefs may be implemented in the form of rules that allow for a somewhat precise pre-selection of cases, that here will be set in terms of two preselection methods, which are depicted below.

The former one is the Template Retrieval one. Under this method, a template is created once a new case is identified, according to which past cases will be pre-selected. The main making facts known in this method are the norms addressed. Thus, under the assumption that cases addressing significantly different norms are different, this method essentially pre-selects cases that have a given amount of norms in common. Given the structure of Portuguese norms, it may do it in three different ways. In fact, Portuguese norms are hierarchically organized into three levels. At the higher one there are Articles, which may have one or more Numbers that, in turn, may have one or more Items, i.e., this method may be configured to compare cases based only on the Article, resulting in a general pre-selection with higher cardinality. On the other hand, it may be arranged to reflect on the Number or even the Item, resulting in a more precise pre-selection of a set of cases but with smaller cardinality. Additionally, a threshold may be established, considering the number of norms that should be contemplated, allowing operations like "selecting all cases that share at least n norms". All these parameters can be configured by an ODR agenda using this 
method. Moreover, multiple iterations can be executed in order to refine the results so far achieved.

In the middle one has Association Rules, which aim to identify the relationships between the values of the particular variables that make up a case. This is a fairly common task in data mining, having a wide range of applications. The main objective is to find hidden patterns that may help to explain or determine the system behaviour. If we think in the legal domain, we may consider rules such as " $60 \%$ of cases in which norms A and B are used by one party, that party wins". In order to support the generation of the rules and select the ones that are essential, statistical machinery may be enforced, in terms of evaluating factors such as the support factor, confidence factor or the expected confidence factor. Generally, only rules that have a confidence factor above a given threshold are considered.

We are mainly interested in rules that encode behaviours such as "in cases in which norm1 and norm 2 are used and the objective of the party is to solve the dispute at all cost, that party wins". The work of selecting the relevant rules is done by a legal practitioner. Although it might be quite an extensive work, it must only be done once. Afterwards, these rules can be used to create categories or classes of cases. Then, cases are assigned to categories according to the rules they comply with.

In order to follow this method, the information contained in the database about the cases is represented according to the vector space model (Salton et al., 1975). This is a fairly simple algebraic model for representing text documents, in which instead of using textual fields, a case is represented as a vector. Specifically, in this work, a case is seen as a vector $\mathrm{V}$ of binary entries, in which each entry $\mathrm{i}<\mathrm{N}$ corresponds to a fixed descriptor from the descriptor vector $\mathrm{D}$ of size $\mathrm{N}$. Thus, the value of each binary entry denotes the presence or absence of that descriptor in the case. Descriptors denote important components of a case (e.g. legal norms, objectives of the party, winner of the case). Thus, one can look at a vector that represents a case and, considering the descriptors vector $\mathrm{D}$, determine which information is or is not present on the case (Figure 1).

$\mathrm{N}$-dimension descriptors vector

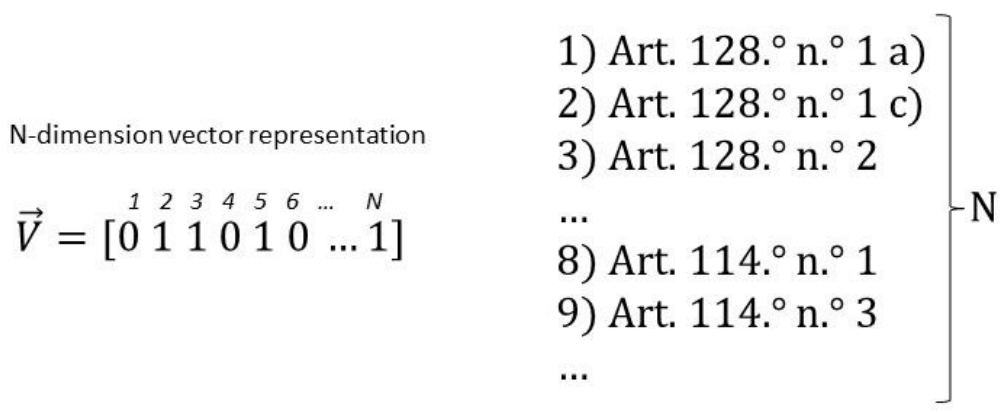

Fig. 1 N-dimension vectorial representation of a case

Basically, this representation of a case allows us to see the norms addressed by each party, which are their objectives and which is the outcome. It is thus a very concise manner of representing all this information, demanding very few resources to handle and to store. Following the same line of thought, a database with $\mathrm{m}$ cases in which each case is described by $\mathrm{N}$ descriptors, can be represented as an $\mathrm{m}-\mathrm{by}-\mathrm{N}$ matrix in which each line is a vector representing a case (Figure 2).

Given this data representation, it is possible, as stated before, to apply association procedures to determine relationships between the data. The objective is to create groups of documents, or cases, in which the same rules return a truth-value true. Then, the retrieval process becomes relatively simple, i.e., whenever cases have to be retrieved for a given problem, the system initially determines which rules return a truth-value true for the new case. This will allow determining to which category the case belongs to. Then, all the cases of that group can be retrieved, as they are potentially similar and appealing to find a solution to the new problem. Basically, this approach consists in classifying cases using association procedures. The purpose is thus to group the cases in such a way that retrieval will be faster. 


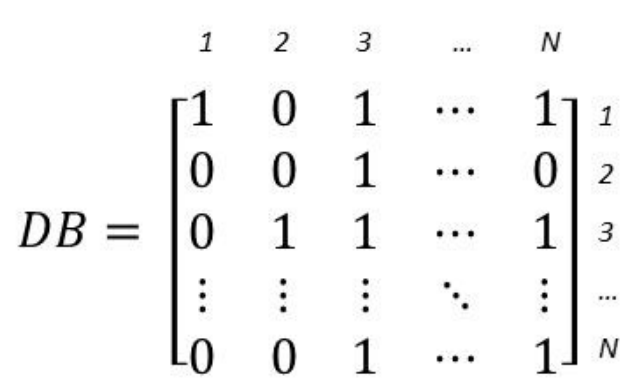

Fig. 2 Representation of a database of cases as a matrix

The main advantage of this method is indeed its effectiveness. Once all the cases of the database are classified, it becomes very easy to retrieve the cases from a given group.

\section{Evaluation}

Concerning the evaluation phase, two methods are presented here. The main purpose of these methods is to compute a value for each case that allows them to be sorted according to some criteria. They implement two different similarity functions that allow to set a value of similarity between two cases. A list of cases can then be sorted according to their similarity with the new case.

Under the former one, we will use a Nearest Neighbour Algorithm (equation 1), which computes a value of similarity between two cases by comparing some of its key features, in the form:

$$
\operatorname{sim}=\begin{gathered}
\sum_{t=1}^{m_{m}} W_{i} * \operatorname{sim}_{i}\left(A T g_{t}^{N}, A T q_{t}^{R}\right) \\
\sum_{i=1}^{n} W_{i}
\end{gathered}
$$

where:

- $\quad \mathrm{n}$ - stands for the number of items to ponder in order to work out a similarity value;

- $\quad \mathrm{Wi}$ - denotes the weight of element $i$ in the whole similarity value ;

- $\quad$ Fsim - refers to the similarity function for element $i$; and

- Arg - denotes the arguments for the similarity function representing the values of the element $i$, for the new case and the retrieved case, namely $\mathrm{N}$ and $\mathrm{R}$.

Basically, the similarity function looks at each of the components that characterize a case and assigns it a value of similarity. Each of these values has a given significance for the working out of the overall similarity value (e.g., the legal norms used by the parties may be much more important than the dates of occurrence of the cases).

It is now time to detail the information of the case that is considered to be relevant for the totalling of the similarity value, i.e., its parts. According to our range of appliance, we consider three kinds of data, namely the objectives stated by each party in the beginning of the dispute, the norms addressed by each party and by the eventual witnesses, and the date of the dispute. Both norms addressed and the objectives are lists of elements, thus the similarity function consists in comparing two lists equation (2). The similarity is higher when the two lists have a superior percentage of common elements. Alike, the similarity function verifies if the two dates are within a given time range, presenting a higher match when the two dates are closer.

$$
\operatorname{fim}_{i \text { ist }}=\frac{\left|L_{N} \cap L_{R}\right|}{n}, n=\left\{\begin{array}{ll}
\left|i_{N}\right|, & \left|L_{N}\right|>\left|I_{R}\right| \\
\left|L_{H}\right|, & \left|L_{N}\right|<\left|L_{H}\right|
\end{array}\right\}
$$

Once all the values of the several similarity functions are combined accordance to their weights, a value of similarity is obtained that describes to which extent a past known case is similar to the new one. By applying this algorithm to each pre-selected cases, it is possible to sort them, in terms of an order relation. 
The second evaluation method presented here relies on the Cosine Similarity (Steinbach et al., 2005). This method makes use of the vectorial representation of the cases to compute the similarity factor. In fact, the similarity between two vectors can be determined by finding the cosine of the angle between them. Given two vectors of attributes $A$ and $B$, with $N$ entries each, the cosine similarity, $\theta$, is determined as shown in equation (3). Once the data is given as vectors of binary entries described previously, the cosine similarity of two cases will range from 0 to 1 , i.e., the two vectors that will compose the angle will never be greater than $90^{\circ}$.

This second method of computing similarity is quite simpler and faster as it uses the vectors of binary entries. However, contrary to the previous similarity function, it does now allow to assign weights to the several components of the case. This may or may not be a disadvantage, depending on the scope of the application.

$$
\sin =\frac{A \cdot B}{\|A\| \mid\|B\|}=\frac{\sum_{i-1}^{N} A_{i} \cdot B_{i}}{\sqrt[2]{\sum_{i=1}^{K}\left(A_{i}\right)^{2}} \cdot \sqrt[2]{\sum_{i=1}^{N}\left(D_{i}\right)^{2}}}
$$

\section{Generation of Useful Knowledge}

There is a whole set of knowledge that parties in conflict may use in order to take better and more informed decisions. Formerly, it must be considered the role of the BATNA (Best Alternative To a Negotiated Agreement) (Notini, 2005). In fact, when parties enter into a negotiation process, they expect to achieve better outcomes than in litigation. It is of utter importance that, during this negotiation process, the parties are aware of the possible results if the negotiation is unsuccessful. In fact, failing to do so may drive the parties into accepting an agreement that they would do better by rejecting it or rejecting one that they would better off enter into. Likewise, the WATNA, or the Worst Alternative to a Negotiated Agreement is equally important. Looking at these two elements, parties can definitively improve their given and take by looking at the whole picture. ODR platforms that embody such concepts as BATNAs and WATNAs can help parties to get better judgments (De Vries et al., 2005). In fact, it will also make sense to consider the MLATNA - Most Likely Outcome for a Negotiated Agreement (Guasco and Robinson, 2007). This concept denotes the most likely outcome scenario if the negotiation process fails. It represents therefore a good starting point for the dispute resolution process to start. Parties may also find it useful to analyze past similar cases and compare them and their outcomes to their current case. This may help the parties to gain a better understanding of their cases, under the assumption that a past case with similar characteristics has a similar outcome.

Indeed, under the framework of the TIARAC project, we are developing methods for compiling this kind of knowledge. The determination of the BATNA and the WATNA is usually well defined in the rulings of The Law, in the form of norms. These norms can be implemented in rulebased systems, which efficiently determine, according to the characteristics of the case under evaluation, the legal boundaries of the outcome. As an example of the drawing on of such rules, it is presented below a listing of Def_Rule 396, an abstract description of the procedures that allow the computation of the BATNA and WATNA for the Portuguese Labour Law, as it is stated in Decree of Law (DL) 7/2009 (Portuguese Laws). This simplified rule considers only the case in which a worker ends the contract with a just cause.

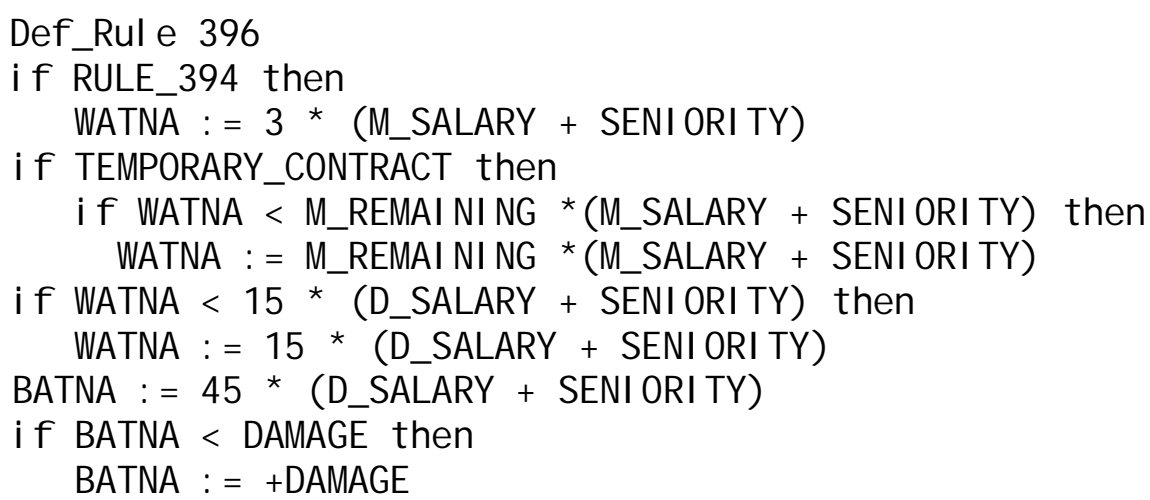


In the same way as MLATNA, the case with the highest value of similarity is chosen, i.e., there is a high probability that the court ruling will match that of the case with the highest similarity value presented by the system. We also find it useful for the parties to have access to past cases, so that they can analyse them and gain a better understanding about its domain of discourse. Besides that, for each selected case, the system also computes the utility of its outcome according to the characteristics of the current case, i.e., the users may acknowledge how much they would gain or lose if the outcome of their cases were the same. Indeed, similar cases may have different outcomes, depending on (in the case of Labour Law) attributes such as worker seniority, wage, and existence or not of extra hours of work not yet paid, among others. In order to be able to compute the utility of the solutions of other cases with respect to the new case, they are structured so that they may be applied to different cases in order to compute its outcomes.

At the end, all this information is presented in a graphical form to the user (Figure 3). Looking at this representation, the user is able to acknowledge the distance between the BATNA and the WATNA (allowing him/her to assess the risk of his/her decisions), to analyse the maximum and minimum utility and similarity values or perform an analysis of similarity versus utility.

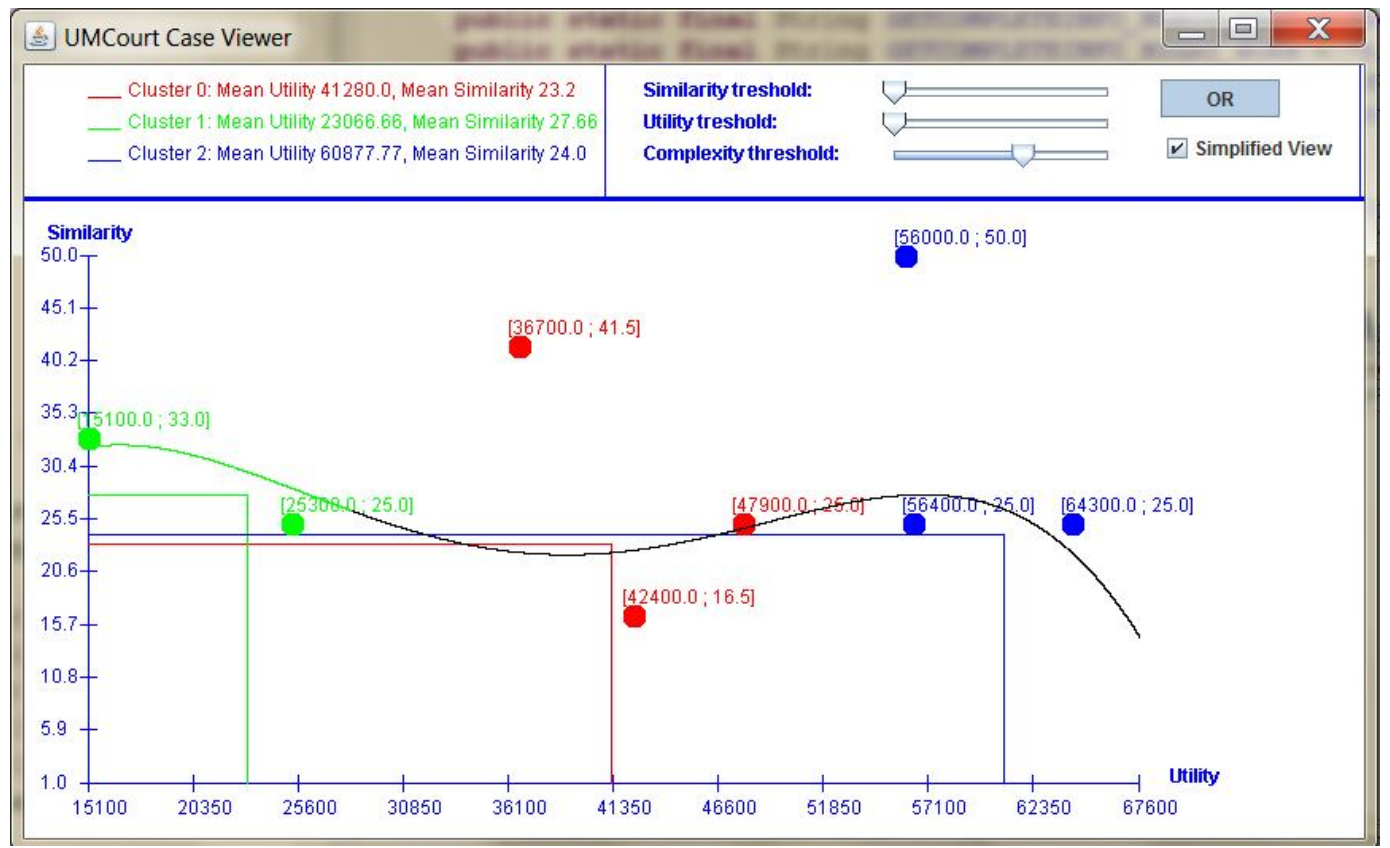

Fig 3 Prototype of the knowledge visualization interface

\subsection{Dynamic Negotiation and Mediation}

Negotiation and mediation are well-established conflict resolution methods whose potential may be increased by using technological means. However, the role of technology in these methods is not being exploited as it could be. As a consequence, an opportunity is being missed to significantly increase the advantages of parties in using these methods. In fact, current technological approaches to negotiation or mediation consist mostly on putting the parties into contact, facilitating message and document exchange, leaving all the important workload to human experts. There are several aspects of the problem that could be improved with an extensive use of technology. One of them is the boost on the information available for the parties to take better decisions, a development that has been addressed in the previous section. Another tendency is related with the fruitful use of context information. In fact, there is a significant amount of data that was available in traditional approaches to negotiation or mediation that was lost with the advent of technology-based communication means. In order to gain back that data, we are pursuing an approach that integrates beginnings from the Ambient Intelligence field with the ones of Computer Science. Therefore, our aim is that parties using these tools will do it within the scope 
of intelligent environments that are able to acquire background information about their users. In that sense, we are interested in information about the level of stress of the users or even of their emotions, if possible. This information can be used by the system to order each user according to given profiles that define the negotiation style and their attitudes.

The main advantage of this approach is that it enables conflict resolution methods that by themselves may adapt to changes that can occur in the conflict resolution style of the parties. Specifically, we are developing mediation and negotiation algorithms that can detect these changes in real time and readapt strategies (Figure 4), so that these changes may be reflected in the process of interaction, increasing effectiveness. Readapting strategies may consist in suggesting different outcomes (e.g. proposing a more favorable outcome for a given party may relax him/her) or in interrupting contact between parties (e.g. in cases in which emotions may rocket). This approach results in dynamic and context-aware methods for conflict resolutions that aim at the increase of the satisfaction of the parties at each moment and thus increasing the possibilities of success.

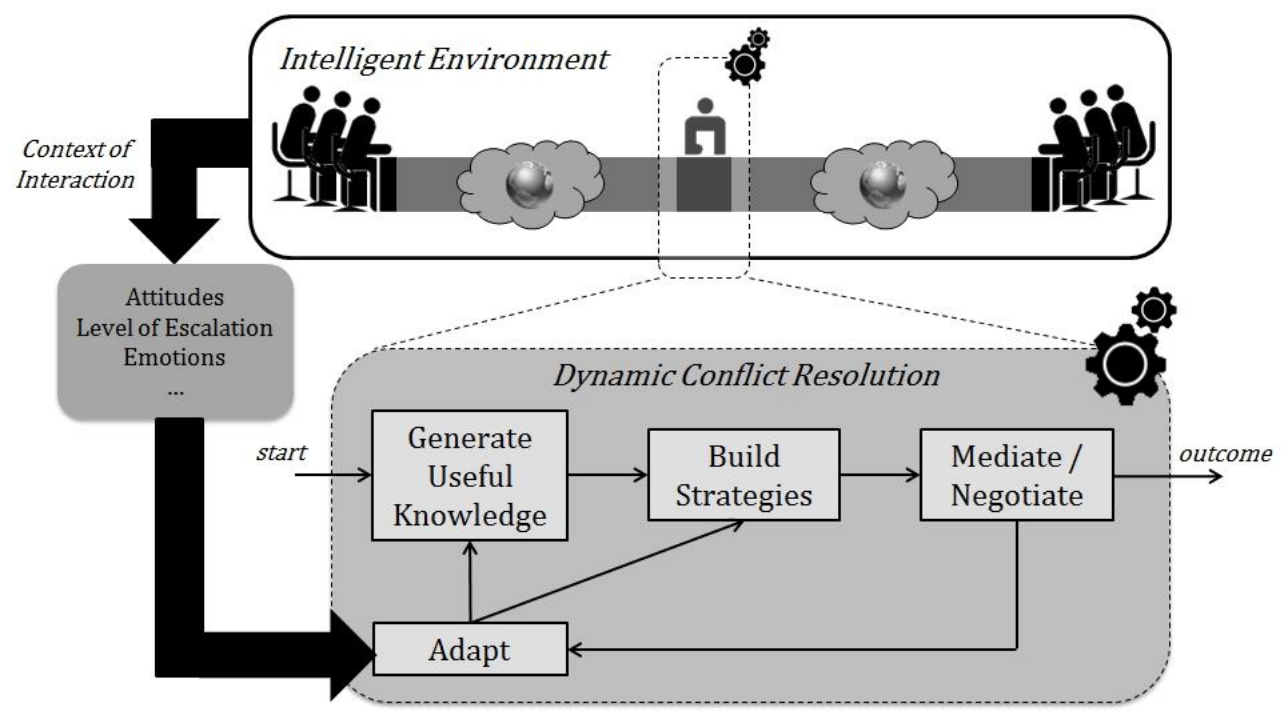

Fig. 4 High level view of the dynamic conflict resolution model that uses information from the context of interaction provided by an intelligent environment

\section{Conclusion}

Despite the existence of some automated systems that operate on well delimited legal domains, the development of fully autonomous ODR systems is still far from what was initially envisioned. In fact, nowadays we cannot talk about intelligent or intuitive ODR tools. After having analyzed some of the major ODR providers, several conclusions may be drawn. The former one is that the human expert still play, in the majority of the systems, a major role, i.e., existing systems have little to no automation at all, with humans performing even the simpler tasks. This still encompasses monetary and time costs that could be reduced. It is a fact that we also conclude that fully autonomous ODR systems are not achievable yet and they may not even be desirable, but there are many simple tasks that could be automated, releasing experts for a different work. Moreover, the interaction with current ODR systems is still a very old-fashioned one. In most of the cases, parties simply provide information through web forms, without any kind of assistance, or even using means external to the ODR system, such as e-mails or faxes, i.e., there is a must of a new form of interaction that not only will be in charge of collecting the needed information but also will support the users throughout the process, providing data, and/or suggesting the consultation of specific documents or even creating new layouts of legal documents.

The use of techniques from AI can however significantly improve the current state of the art in this field. Thus, it is our conviction that research should aim at the development of fully automated systems based on techniques borrowed from AI. As most of the current literature on this topic 
does, we realize that this objective is rather utopic. However, independently of its accomplishment, the important point is that in the path to achieve it, new intelligent tools that can intuitively be used by the persons involved in legal disputes emerge. These tools will ultimately provide a faster and more efficient access to justice, making it indeed fairer. The development of these advanced expert systems will, in our opinion, rely on two different AI techniques. On the one hand, we conclude that purely rule-based systems are not feasible as they make a closed interpretation of The Law while The Law is open to many different interpretations. On the other hand, we also conclude that purely case-based systems can become slow and inefficient. The path to follow will rely on a hybrid approach, merging the simplicity of a rule-based system with the completeness of a casebased one.

By combining these two techniques, we believe that the development of ODR systems that can implement efficient intelligent behaviors will soon become a reality. These systems will consist, at a first stage, on decision support and information systems aimed at empowering the users through the provision of relevant information and support for better and weighted decision-making processes. Once such systems are accomplished, the role of the users in the dispute resolution process will be enhanced. We believe that this will lead to more transparent legal disputes in which the efficient access to relevant information will improve the success rate of the dispute resolution processes, increasing the satisfaction of the parties.

Acknowledgments. The work described in this paper is included in TIARAC - Telematics and Artificial Intelligence in Alternative Conflict Resolution Project (PTDC/JUR/71354/2006), which is a research project supported by FCT (Science \& Technology Foundation), Portugal. The work of Davide Carneiro is also supported by a doctoral grant by FCT (SFRH/BD/64890/2009).

\section{References}

Aamodt A., Plaza E. (1994). Case-based reasoning: Foundational issues, methodological variations, and system approaches. In: AI Communications, 7(1):39-59. IOS Press.

Aleven, V. (1997). Teaching case-based argumentation through a model and examples. PhD thesis, University of Pittsburgh.

Ashley, K. D. \& Aleven V. (1991). Toward an intelligent tutoring system for teaching law students to argue with cases. Proceedings of the $3^{\text {rd }}$ international conference on Artificial intelligence and Law, pp. 42--52, ACM, New York.

Ashley, K.D. (1991). Modeling Legal Arguments: Reasoning with Cases and Hypotheticals. The MIT Press.

Ashley, K.D. (2004). Case-Based Models of Legal Reasoning in a Civil Law Context. International Congress of Comparative Cultures and Legal Systems of the Instituto de Investigaciones Jurídicas.

Beer, M., d'Inverno, M., Jennings, N. R., Luck, M., Preist, C. \& Schroeder, M. (1999). Negotiation in Multi-Agent Systems. Knowledge Engineering Review, 14 (3). pp. 285--289.

Bellucci, E., \& Zeleznikow, J. (2001). Representations of decision-making support in negotiation. In Journal of decision systems, 10(3-4), pp. 449-479.

Benjamins, R. V., Casanovas, P., Breuker, J. and Gangemi, A. (2005). Law and the Semantic Web: Legal Ontologies, Methodologies, Legal Information Retrieval, and Applications.

Bennett, S. C. (2002). Arbitration: essential concepts. ALM Publishing.

Bonczek, R. H., Holsapple, C. W., \& Whinston, A. B. (1981). Foundations of decision support systems. Academic Press.

Brachman, R., \& Levesque, H. (2004). Knowledge Representation and Reasoning. Morgan Kaufmann.

Brams, S.J. \& Taylor, A.D. (1996). Fair Division: From cake cutting to dispute resolution. Cambridge University Press.

Brown, H. \& Marriott, A. (1999). ADR Principles and Practice. Sweet and Maxwell.

Buchanan, B., \& Headrick, T. (1970). Some Speculation about Artificial Intelligence and Legal Reasoning, Stanford Law Review, Vol. 23 No. 1, pp. 40--62. 
Cáceres, E. (2008). EXPERTIUS: A Mexican Judicial Decision-Support System in the Field of Family law. In Francesconi, E. B. E., Sartor, G., \& Tiscornia, D. (Eds.), Legal Knowledge and Information Systems (pp. 78-87). IOS Press.

Corcho, O., Fernández-lópez , M., Gómez-pérez, A. and López, A. Building legal ontologies with methontology and webode. (2005). Law and the Semantic Web.

De Vries, B.R., Leenes, R., Zeleznikow, J. (2005). Fundamentals of providing negotiation support online: the need for developing BATNAs. Proceedings of the Second International ODR Workshop, Tilburg, Wolf Legal Publishers, pp- 59-67.

Forsyth, R. (1986). The Anatomy of Expert Systems. In: Yazdani, M. (ed.) Artificial Intelligence: Principles and Applications, ch. 8, pp. 186-187. Chapman \& Hall: London.

Greinke, A. (1994). Legal Expert Systems - A Humanistic Critique of Mechanical Legal Inference. Murdoch University Electronic Journal of Law, Vol. 1, Num. 4.

Gruber, T. R. (1993). A translation approach to portable ontologies. Knowledge Acquisition, 5(2):199-220.

Guasco, M. P., \& Robinson, P. R. (2007). Principles of negotiation. Entrepreneur Press.

Harmon, P. \& King, D. (1985). Expert Systems: Artificial Intelligence in Business. John Wiley \& Sons: New York.

Hayes-Roth, F., Waterman, D. A., \& Lenat, D. B. (1983). Building expert systems. AddisonWesley Longman Publishing Co., Inc. Boston, MA, USA.

Jackson, P. (1990). Introduction to expert systems. Addison-Wesley Longman Publishing Co., Inc. Boston, MA, USA.

Katsh, E., Rifkin, J., \& Gaitenby, A. (1999). E-Commerce, E-Disputes, and E-Dispute Resolution: In the Shadow of eBay Law. Ohio State Journal on Dispute Resolution, 15, 705.

Katsh E. and Rifkin J. (2001). Online dispute resolution - resolving conflicts in cyberspace. Jossey-Bass Wiley Company, San Francisco.

Kolodner, J. L. (1992). An introduction to case-based reasoning. Artificial Intelligence Review, 6(1), 3-34. doi: 10.1007/BF00155578.

Kolodner, J. L (1993). Case-based Reasoning. Morgan Kaufmann Publishers.

Landes, W. M., \& Posner, R. A. (1976). Legal precedent: A theoretical and empirical analysis. Journal of Law and Economics, 19, 249.

Lodder, A., \& Thiessen, E. (2003). The role of artificial intelligence in online dispute resolution. In Workshop on Online Dispute Resolution at the International Conference on Artificial Intelligence and Law, Edinburgh, UK.

Lodder, A.R. (2006). The Third Party and Beyond. An Analysis of the Different Parties, in particular The Fifth, Involved in Online Dispute Resolution. Information \& Communications Technology Law, 15(2):143-155.

Lodder, A. R. \& Zeleznikow, J. (2010). Enhanced Dispute Resolution Through the Use of Information Technology. Cambridge Unversity Press, ISBN: 978-0521515429.

Matthijssen, L. (1995). An intelligent interface for legal databases. Proceedings of the 5th international conference on Artificial intelligence and law. ACM, New York.

Matthijssen, L. (1999). Interfacing Between Lawyers and Computers: An Architecture for Knowledge-Based Interfaces to Legal Databases (Law and Electronic Commerce). Kluwer Law International.

Notini, J. (2005). Effective Alternatives Analysis In Mediation: "BATNA/WATNA" Analysis Demystified. Available at http://www.mediate.com/articles/notini1.cfm. Accessed in 05/2005

Olson, G. M., Malone, T. W., and Smith, J. B. (Ed.). (2001). Coordination Theory and Collaboration Technology. Mahwah, NJ: Erlbaum, 2001.

Oskamp, A., Tragter, M., \& Groendijk C. (1995) AI and Law: What About the Future?. Artificial Intelligence and Law, Vol. 3, N. 3, pp. 209-- 215.

Parunak, H. V. D. (1997). Go to the ant: Engineering principles from natural multi-agent systems. Annals of Operations Research, 75, pp. 69-102.

Peruginelli, G. (2002). Artificial Intelligence in Alternative Dispute Resolution. In Sartor, G.

(Eds.) Proceedings of the workshop on the Law of Electronic Agents (LEA02).

Popple, J. (1991). Legal expert systems: The inadequacy of a rule-based approach. Australian Computer Journal, Vol. 23, Num. 1.

Popple, J. (1996). A Pragmatic Legal Expert System. Applied Legal Philosophy Series. Ashgate, Dartmouth.

Rahwan, I. \& Simari, G. (Eds.). (2009). Argumentation in Artificial Intelligence. Springer. 
Raiffa, H. (2002). The Art and Science of Negotiation. Harvard University Press.

Searle, J.R. (1980). Minds, Brains and Programs. In Behavioral and Brain Sciences 3 (3), pp. 417-457.

Sowa, J. F. (2000). Knowledge representation: logical, philosophical, and computational foundations. MIT Press.

Salton, G., Wong, A., Yang, C. S. 1975. A vector space model for automatic indexing. In Communications of the ACM, v.18 n.11, 613-620.

Span, G. (1993). LITES, an intelligent tutoring system for legal problem solving in the domain of Dutch Civil law. Proceedings of the $4^{\text {th }}$ international conference on Artificial intelligence and Law, pp. 76-81. ACM, New York.

Steinbach, M., Tan P. N. and Kumar, V. (Eds). 2005. Introduction to Data Mining. Pearson Addison Wesley.

Susskind, R. (1987). Expert Systems in Law: A Jurisprudential Inquiry. Clarendon Press: Oxford.

Sycara, K. (1993). Machine Learning for Intelligent Support of Conflict Resolution, Decision Support Systems, 10:121-136.

Thiessen, E.M. (1993). ICANS: An Interactive Computer-Assisted Multi-party Negotiation Support System. PhD Dissertation, School of Civil \& Environmental Engineering, Cornell University, Ithaca, NY.

Thiessen, E. M., and Fraser, K. (2003). Mobile ODR with SmartSettle. In Proceedings of the UNECE Forum on ODR.

Turban, E. (1993). Decision support and expert systems: management support systems. Prentice Hall PTR Upper Saddle River, NJ, USA.

Turing, A.M. (1950). Computing machinery and intelligence. Mind, 59, pp. 433-460.

Tyler C. (2005). 115 and Counting: The State of ODR 2004. In Conley Tyler, Melissa, Katsh, Ethan and Choi, Daewon (Eds.), Proceedings of the Third Annual Forum on Online Dispute Resolution. International Conflict Resolution Centre, University of Melbourne in collaboration with the United Nations Economic and Social Commission for Asia and the Pacific.

Velasquez, J. D. (1997). Modeling emotions and other motivations in synthetic agents. In Proceedings of the National Conference on Artificial Intelligence (pp. 10-15). John Wiley \& Sons.

Visser, P.R.S., Bench-Capon, T.J.M. (1998). A Comparison of Four Ontologies for the Design of Legal Knowledge Systems. Artificial Intelligence and Law, Volume 6, Number 1, pp. 27-57.

Waterman, D.A. \& Peterson, M. (1980). Rule-based models of legal expertise. In the Proceedings of the First National Conference on Artificial Intelligence, Stanford University.

Watson, I. (1997). Applying Case-Based Reasoning: Techniques for Enterprise Systems. Morgan Kaufmann.

Wooldridge, M. \& Jennings, N.R. (1995). Intelligent Agents: theory and practice. In: The Knowledge Engineering Review, p. 115-152.

Zeleznikow, J., \& Hunter, D. (1994). Building Intelligent Legal Information Systems: Representation and Reasoning in Law. pp. 230--37.

Zeleznikow J. \& Stranieri A. (1995). The split-up system: integrating neural networks and rulebased reasoning in the legal domain. Proceedings of the $5^{\text {th }}$ international conference on Artificial intelligence and law. pp. 185--194.

Zeleznikow, J., \& Bellucci, E. (2003). Family_Winner: integrating game theory and heuristics to provide negotiation support. In Proceedings of Sixteenth International Conference on Legal Knowledge Based System (pp. 21-30).

Zeleznikow, J., \& Bellucci, E. (2004). Building negotiation decision support systems by integrating game theory and heuristics. In Proceedings of the IFIP International Conference on Decision Support Systems.

Zweigert, K. \& Kötz, H. (1998). An Introduction to Comparative Law, Clarendon Press, 3rd edition. 